\title{
PENETRATING ABDOMINAL INJURIES IN ADULTS SEEN AT TWO TEACHING HOSPITALS IN GHANA
}

\author{
M. OHENE-YEBOAH ${ }^{1}$, J. C. B. DAKUBO ${ }^{2}$, F. BOAKYE ${ }^{1}$ and S. B. NAEEDER ${ }^{2}$ \\ ${ }^{1}$ Department of Surgery, School of Medical Sciences, Kwame Nkrumah University of Science and \\ Technology, University Post Office, PMB, Kumasi, Ghana and Department of Surgery, Komfo Anokye \\ Teaching Hospital, Kumasi, Ghana ${ }^{2}$ Department of Surgery, University of Ghana Medical School, Accra
}

Corresponding Author: Dr. Micheal. Ohene-Yeaboah

Conflict of Interest: None declared

\section{SUMMARY}

Background: The incidence of penetrating abdominal injuries (PAI) has increased in the West African sub-region.

Objective: To determine the pattern and management outcome of penetrating abdominal injuries (PAI) in the two main teaching hospitals in Ghana.

Study Design: A prospective and retrospective descriptive study.

Setting: Komfo Anokye Teaching Hospital (KATH), Kumasi and Korle-Bu Teaching Hospital (KBTH), Accra.

Methods: Relevant details of all adult patients admitted with penetrating abdominal injuries over a 11-year period were recorded at KATH and KBTH in Accra. The study in KATH was prospective pro forma based and that in the KBTH was a retrospective case review of all penetrating abdominal injuries.

Results: There were 411 patients, mostly men (M: F-8:1). The peak age of patients was 20-29 years, 164 patients (39.9\%). Abdominal stab wound injuries accounted for $251(61.1 \%)$. Three hundred and thirty - one patients $(80.5 \%)$ had an emergency laparotomy. Twelve patients required 16 emergency thoracotomies. The small bowel (23.2\%), stomach (12.9\%), colon (10.2\%), the liver $(10.0 \%)$, were the most commonly injured organs. In 92 patients $(29.0 \%)$ no significant intraabdominal injury was detected at laparotomy Conclusion: Stab wounds are the main penetrating abdominal injuries seen mostly among young male adults in Ghana. Management was by a mandatory laparotomy after clinical assessment. The overall mortality was $4.4 \%$. Selective non-operative management of abdominal stab wounds is possible.

Keywords: Abdominal Injuries, Penetrating, Mandatory Laparotomy, Non-operative management
Email:mikeoheneyeboah@yahoo.co.uk

\section{INTRODUCTION}

In Ghana and other countries of the West African subregion, the pressures of severe economic conditions and rapid social change have led to an increase in social conflict and violent crime especially in the rapidly expanding urban centers. ${ }^{1-3}$ The proliferation of small arms - following civil wars and internal armed changes of the political process in many countries in the sub-region - has increased the crime rate and thus the incidence of penetrating abdominal injuries. ${ }^{2}$ Previous studies have highlighted the economic impact of the increased incidence of trauma in the sub region as the injuries affect mostly the productive sector of the population. ${ }^{4}$

It is nearly three decades now since Archampong and Naaeder reported on the patterns of abdominal injuries in Accra a city with a population similar to Kumasi. ${ }^{1,5}$ A more recent report from the two major communities in Ghana (Accra and Kumasi) focused on blunt abdominal injuries. ${ }^{4}$

Over the past two decades hospital records in Kumasi show increasing numbers of patients reporting for treatment for abdominal stab wounds and civilian gunshot wounds. There is no recent report on the pattern of these penetrating abdominal injuries or the outcome of treatment. Unlike blunt abdominal injuries a mandatory laparotomy has been the traditional approach to penetrating abdominal injuries. ${ }^{6-8}$

Following the landmark report by $\operatorname{Shaftan}^{9}$ on the selective non-operative management of abdominal stab wounds, the treatment of penetrating abdominal injuries has been changing. In many trauma centres world-wide, the management of penetrating abdominal injuries remains controversial and subjected to constant reappraisal. ${ }^{10-14}$

It is against this background that this study was designed and conducted. 
This is a report on the pattern and outcome of treatment of penetrating abdominal injuries as seen in the two major communities in Ghana

\section{PATIENTS AND METHODS}

Over two 11- year periods, clinical data were collected and recorded from the Komfo Anokye Teaching Hospital (KATH) Kumasi and the Korle$\mathrm{Bu}$ Teaching Hospital (KBTH) Accra on adult patients admitted with penetrating abdominal injuries (PAI).

The KATH study was prospective using a proforma between January 1998 and December 2002 combined with a retrospective analysis of patient case notes from January 2003 to December 2008. The KBTH study was a retrospective patients' case notes review from July 1998 to June 2008.

In the prospective study a specially designed proforma was completed for each patient. The retrospective studies consisted of data obtained from patients' case notes, admission and discharge registers, the theatre and recovery ward records, and the nurses' report books.

Recorded data included, among others, the basic demography of patients, the cause of injury, clinical findings, operative findings, organs injured, associated extra abdominal injuries, treatment and outcome. The data was analyzed over two time periods, 1998-2002 and 2003- 2008 in order to reveal any changing trends over time.

\section{RESULTS}

\section{Patient characteristics}

Four hundred and eleven adult patients with PAI were admitted and treated at the two teaching hospitals over the study periods; 207 in KATH and 204 in KBTH. There were 366 males and 45 females giving a male preponderance (M: $\mathrm{F}=$ 9.1:1). The peak age incidence was 20-29 years; accounting for 164 patients $(39.9 \%)$, followed by 30-39 years with 112 patients $(27.3 \%)$, figure 1 . Thus the majority of the patients were under 40 years of age $-328(79.8 \%)$,

\section{Injury Patterns}

Two hundred and fifty- one patients $(61.1 \%)$ were treated for abdominal stab wounds (ASW); 144 in KATH and 107 in KBTH. Forty - seven and 38 patients were treated for abdominal gunshot wounds (AGW) in KATH and KBTH respectively accounting for a total of 85 patients or $20.7 \%$ of the PAI patients.
There were more PAI due to road traffic accidents (RTA) in the KBTH series (38) than in the KATH series (7). These RTA injuries accounted for 48 (11.7\% of all the PAI seen (Table 1). Other less frequent causes of PAI were impalement injuries 11 patients, flying objects 7 patients, and falls from heights 9 patients accounted for less than $10 \%$ of the PAI patients (Table 1).

Figure 1 Age and sex distribution of adult patients with penetrating abdominal injuries.

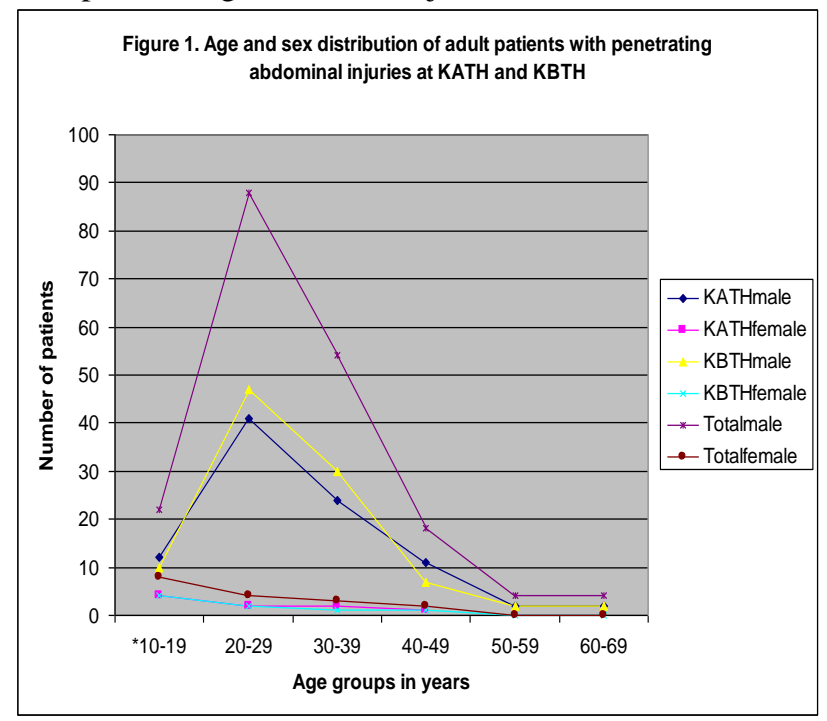

Table 1 Mechanism of injury in 411 patients treated for penetrating abdominal wounds

\begin{tabular}{|l|c|c|}
\hline \multicolumn{1}{|c|}{ Type of injury } & n & \% \\
\hline Stab wound & 251 & 61.1 \\
\hline Gunshot wound & 85 & 20.7 \\
\hline RTA & 48 & 11.7 \\
\hline Impalement & 11 & 2.7 \\
\hline Flying objects & 7 & 1.7 \\
\hline Falls from height & 9 & 2.2 \\
\hline Total & 411 & 100 \\
\hline
\end{tabular}

Table 2 is a summary of the intra-abdominal organs injured. Associated extra-abdominal injuries occurred in $39(15.5 \%)$ patients (mostly from GSW) and this had a significant bearing on the mortality.

The types of associated extra- abdominal injuries seen are shown in Table 3.

\section{Surgical operations}

Of the 411 patients seen and treated for PAI 331 $(80.5 \%)$ had an emergency laparotomy. Of 311 laparotomies, 187(56.5\%), were performed for 
peritonitis, $95(30.5 \%)$ for evisceration of abdominal contents and 49(14.8\%) for haemoperitoneum. In $92(29.6 \%)$ of these (331) laparotomies no abnormality was found at operation.

Table 2 Frequency of organ in jury in 411 patients treated for PAI

\begin{tabular}{|l|c|c|}
\hline Organ & Frequency & \% \\
\hline Small bowel & 100 & 23.2 \\
\hline Ant. Abd. wall & 91 & 21.1 \\
\hline Stomach & 56 & 12.9 \\
\hline Colon & 44 & 10.2 \\
\hline Liver & 43 & 10.0 \\
\hline Omentum & 32 & 7.4 \\
\hline Spleen & 20 & 4.6 \\
\hline Bladder & 12 & 2.8 \\
\hline Gall Bladder & 12 & 2.8 \\
\hline Diaphragm & 9 & 2.1 \\
\hline Mesentery & 4 & 0.9 \\
\hline Pancreas & 5 & 1.2 \\
\hline Great vessels & 2 & 0.5 \\
\hline Kidney & 1 & 0.2 \\
\hline
\end{tabular}

Table 3 Associated extra abdominal injuries in patients penetrating abdominal injuries

\begin{tabular}{|l|c|c|c|c|c|}
\hline & KATH & KBTH & GSW & SW & TOTAL \\
\hline Chest injury & 5 & 1 & 4 & 2 & 6 \\
\hline $\begin{array}{l}\text { Long bone } \\
\text { fractures }\end{array}$ & 3 & 3 & 6 & 0 & 6 \\
\hline $\begin{array}{l}\text { Spine inju- } \\
\text { ries }\end{array}$ & 1 & 2 & 2 & 1 & 3 \\
\hline $\begin{array}{l}\text { Soft tissue } \\
\text { injuries }\end{array}$ & 3 & 2 & 3 & 2 & 5 \\
\hline Total & 12 & 8 & 15 & 5 & 20 \\
\hline
\end{tabular}

Gastro-intestinal perforations - the most common intra-abdominal injuries seen (Table2)- were closed by direct simple suture, except where multiple perforations of the small bowel were close to each other then resection and anastomoses was done. Four cases of abdominal stab wounds and 6 of gunshot wounds to the left colon required a colostomy.

Penetrating injuries to the liver were treated by packing, blood transfusion and debridementt of devitalized liver tissue. All eleven injured spleens were treated by splenectomy. Injuries to the gall bladder were treated by a cholecystectomy.

Lacerations of the omentum and small bowel mesentery were treated by excision, suture or bowel resection and anastomoses where the blood supply to the involved intestinal segment was considered as compromised.

Urinary bladder injuries were sutured with continuous drainage for 14 days. In 67 patients $16.3 \%$ of all PAI, surgery was limited to wound exploration only as there was no evidence of penetration of the peritoneal cavity. Of 92 negative laparotomies, 51 were at KATH and 41 at KBTH. The overall negative laparotomy rate was $29.0 \%$. The overall laparotomy rates was $80.5 \%$. All associated extra-abdominal injuries (Table 3) were treated appropriately. The overall results were similar across the years of the study. There were no differences in the patterns of the injuries and outcome of treatment recorded between the periods of 19982003 and 2003-2008. The pattern of injury, treatment and outcome are shown in Table 4.

Table 4 Treatment and outcome of 411 patients admitted with penetrating abdominal wounds

\begin{tabular}{|l|c|c|c|c|c|c|}
\hline \multicolumn{1}{|c|}{ Injury (n) } & $\begin{array}{c}\text { Laparotomy } \\
(\boldsymbol{\%})\end{array}$ & $\begin{array}{c}\text { Wound Ex- } \\
\text { ploration }\end{array}$ & $\begin{array}{c}\text { Non-operative } \\
\text { Treatment }\end{array}$ & $\begin{array}{c}\text { Number of } \\
\text { laparotomies } \\
\text { with normal } \\
\text { findings }\end{array}$ & $\begin{array}{c}\text { Percentage of } \\
\text { normal lapa- } \\
\text { rotomies }\end{array}$ & $\begin{array}{c}\text { Mortality } \\
\mathbf{n}(\%)\end{array}$ \\
\hline Stab Wound (251) & $215(85.7)$ & 36 & 0 & 72 & 33.5 \\
\hline Gunshot ( 85) & $77(90.6)$ & 5 & 3 & 14 & $3(1.2)$ \\
\hline RTA (48) & $24(50.0)$ & 16 & 8 & 3 & 12.2 & 12.5 \\
\hline Impalement (11) & $8(72.7)$ & 3 & 0 & 2 & 25.0 & 0 \\
\hline Flying objects (7) & $3(42.9)$ & 4 & 0 & 0 & 0 \\
\hline Falls from heights (9) & $4(44.4)$ & 3 & 2 & 1 & 0 \\
\hline Total (411) & $\mathbf{3 3 1}(\mathbf{8 0 . 5})$ & $\mathbf{6 7}$ & $\mathbf{1 3}$ & $\mathbf{9 2}$ & 25.0 \\
\hline
\end{tabular}

\section{Mortality and morbidity}

There was 18 deaths, 12 at KATH and 6 at KBTH, giving an overall mortality of $4.4 \%$. Eleven of these deaths $(61.1 \%)$ occurred within 24-48 hours after operation and were due to refractory haemorrhage from multiple injuries (Table 5); eight from gunshot wounds and three from RTA. Endotoxic shock due to severe sepsis was the cause of death in five patients. 
In three of these patients, severe peritonitis followed multiple small bowel, gastric and colonic perforations from gunshot wounds. These gunshot wounds occurred as a result of an armed- robbery attack one patient and a hunting accident in the other patient who presented after four days. All the three patients died in the postoperative period.

Table 5 Number of injuries in 11post-operative deaths due to refractory haemorrhage

\begin{tabular}{|l|l|l|l|l|l|}
\hline No. & Sex & Age & Injury & $\begin{array}{l}\text { No. of intra- } \\
\text { abdominal } \\
\text { organ inju- } \\
\text { ries }\end{array}$ & $\begin{array}{l}\text { Associated Ex- } \\
\text { tra- Abdominal }\end{array}$ \\
\hline 1. & M & 22 & GSW & 5 & $\begin{array}{l}\text { Spine fracture } \\
\text { LI\&L5 }\end{array}$ \\
\hline 2. & m & 25 & GSW & 7 & $\begin{array}{l}\text { Contusion of left } \\
\text { Psoas muscles }\end{array}$ \\
\hline 3. & m & 55 & GSW & 3 & Nil \\
\hline 4. & M & 41 & GSW & 4 & Fracture \\
\hline 5. & M & 35 & GSW & 1 & $\begin{array}{l}\text { Bilateral } \\
\text { haemothorax, } \\
\text { fractured spine, } \\
\text { ruptured aorta }\end{array}$ \\
\hline 6. & M & 38 & GSW & 1 & Left haemothorax \\
\hline 8. & M & 27 & GSW & 1 & $\begin{array}{l}\text { Bilateral } \\
\text { haemothorax }\end{array}$ \\
\hline 9. & M & 29 & GSW & 2 & $\begin{array}{l}\text { Bilateral haemo- } \\
\text { pneumothorax, } \\
\text { fracture left hu- } \\
\text { merus }\end{array}$ \\
\hline 10. & F & 22 & SW & 4 & $\begin{array}{l}\text { Bilateral femoral } \\
\text { shaft fractures }\end{array}$ \\
\hline 11. & M & 22 & GSW & 6 & $\begin{array}{l}\text { Nil } \\
\text { tissue lacerations } \\
\text { and crush injuries }\end{array}$ \\
\hline
\end{tabular}

The other two septic patients had associated spine injury, paraplegia and bedsores. Two patients died from respiratory distress, one following fluid over-load and the other from neck wounds involving the trachea in an attempt to commit suicide. The post operative complications were infected wounds in 56 patients (13.6\%), intra-abdominal abscesses 63 patients $(15.3 \%)$ and entero-cutaneous fistula in 23 patients (5.6\%) The negative laparotomy rate was $29.0 \%$. The overall mortality was $4.4 \%$.

\section{DISCUSSION}

The objective of this study was to report on the pattern of PAI in Ghana. ASW were the most common type of penetrating injuries accounting for $61.1 \%$ of all the PAI patients seen and treated. AGW were seen in fewer patients $(20.7 \%$.). These abdominal stab and gunshot wounds were the main types of PAI in our communities as these injuries accounted for over $80 \%$ of the series. This finding is similar to the findings reported from other centres. ${ }^{1-2,6-9}$

Abdominal stab and gunshot wounds were far more common in young Ghanaian men than women with an overwhelming ratio of 8 men to one woman. The circumstances of these injuries are mostly armedrobbery and social conflict in a male-dominated environment. This may explain this nearly exclusive male disease pattern. Over two-thirds of the affected men were less than 40 years old and many of these (39.9\%) were in the age range $20-29$ years.

As pointed out by other workers ${ }^{4}$ this is the most productive sector of the population, with serious implications for the national economy and the families that depend in these young traders, farmers, artisans and businessmen. ${ }^{15}$ Armed robbery attacks, accidents during hunting expeditions, social conflict, unrestricted assess to alcoholic drinks, increasing crime rate mostly manifestations of rapid social change, economic pressures and weakened social authority- are the likely factors accounting for the large numbers of ASW in these young men.

Similar observations were recorded by previous investigators. ${ }^{1,2,5,16}$ With improvements in the economy and more effective law-enforcing methods social conflicts and crime rate may both decrease and thus reduce the incidence of these penetrating injuries. The other causes of these injuries accounted for less than $10 \%$ of the series. The pattern of PAI in this series is similar to that in previous published series. ${ }^{1-2,7,8,16}$

Survival after PAI is dependent on many factors including the organ affected, the presence of multiple intra - abdominal organ injuries and associated chest and long bones injuries. ${ }^{17}$ Early diagnosis and effective treatment of these injuries is critical in improving survival. The modern management of ASW varies widely in different trauma centers.

Routine or mandatory exploration of the abdomen was the traditional approach until the hallmark report by Shatan in $1960 .^{9}$ His initial success with the use of 'surgical judgment' in the selective conservative management of ASW has been repeated using serial physical examinations alone. The negative laparotomy rates reported in the studies using serial physical examination alone has been less than $5 \% .^{10-14}$

In this series the negative laparotomy rate for ASW was $28.7 \%$. This high rate of unnecessary laparotomies is due to the fact that many surgeons working in Kumasi and Accra still adhere to the traditional mandatory laparotomy concept. The use of 
modern ancillary tools such as peritoneal lavage, ultrasonography, laparoscopy and CT scan to increase the likelihood of detecting significant intra-abdominal injury before the abdomen is explored, may have lowered the negative laparotomy rate and the over - all laparotomy rate of $80.5 \%$ in this series.

These facilities are not widely available in most hospitals Ghana and in many other countries of the West African Sub region. The use of serial or repeated physical examination in the management of our patients may prove the way forward as has been the case in many other centres. ${ }^{7-9}$

In the present series $90 \%$ of the patients who sustained gunshot wounds to the abdomen (AGW) had a laparotomy. In almost a fifth of these laparotomies the operation did not reveal any organ damage requiring repair. The overall survival rate of $85.9 \%$ is the same as that from other centres where a policy of selective conservative management of AGW was practiced. ${ }^{10-}$ 14,18 An acceptable survival rate is therefore possible without the practice of a mandatory laparotomy for AGW.

The negative laparotomy rate for $\mathrm{AGW}$ in this series was $18.2 \%$.This finding is consistent with previous reports of rates of $15-27 \%$ for mandatory exploration of $\mathrm{AGW}$ for all cases in which peritoneal penetration was suspected. ${ }^{19}$ The complication rate for unnecessary laparotomies has been quoted to be as high as $41 \% .^{20}$

These unnecessary laparotomies extended length of hospital of patients to over 8 days. ${ }^{21}$ In low income countries such as Ghana ${ }^{22}$ with limited health care resources avoiding unnecessary laparotomies may translate to significant hospital savings as has been reported from other hospitals. ${ }^{23}$

The findings of this study will support the selective nonoperative management of gunshot wounds as has been advocated by a number of trauma centres. ${ }^{10-14}$ However in many hospitals in West Africa including our own, the nonoperative management of AGW remains the exception rather than the rule. Many surgeons working in low income countries may be reluctant to use the selective non operative approach to the management of abdominal AGWs.

The basis of this caution - as is the case in the management of ASWs - is that the selection of patients requires the frequent application of modern ancillary tools of detecting significant intra - abdominal injury. These tools are not readily available in most hospitals in Sub-region. As discussed in the management of ASWs repeated or serial physical examination has proved effective and safe and should be applied to the management of AGWs. ${ }^{10}$

Mortality from gunshot wounds (14.1\%) was much higher than that from stab wounds $(2.1 \%)$ (Table 4$)$. The $14.1 \%$ mortality rate for gunshot wounds in this series is consistent with figures of $12.0 \%$ published from large centres that manage gunshot wounds of the abdomen. $^{24}$

The lethal nature of these gunshot wounds is not unexpected and underscores the need for prompt intervention to reduce the associated mortality. $1,21,24$ The overall mortality of $4.4 \%$ is very similar to the $3.4 \%$, reported in a series of PAI 15 years ago ${ }^{2}$ but slightly lower than the figure of $5.8 \%$ for blunt abdominal injuries previously published. ${ }^{4}$

\section{CONCLUSION}

In conclusion abdominal stab and gunshot wounds cause considerable morbidity and mortality in young Ghanaian men. Gastro-intestinal perforations and the resulting peritonitis are the major cause of morbidity. The mortality from severe blood loss is much higher than from peritonitis. Also gun-shot wounds are associated with a higher mortality. The high negative laparotomy rate may be an indication that many patients with PAI may not require a laparotomy.

\section{REFERENCES}

1. Naaeder SB. Patterns of abdominal injuries in Korle Bu Teaching Hospital, Accra. Ghana Med. J. 1990:24 186-190.

2. Adesanya AA,Afolabi JR. da Rocha - Afodu JT. Civilian Abdominal Gunshot Wounds in Lagos. $J$ $R$ Coll Surg Edinb. 1998 43(4): 230-234.

3. Mohamed AZ, Edino ST, Ochicha O, Umar AB. Epidemiology of gunshot injuries in Kano, Nigeria. Nigerian J Surg Researh. 2005;7(3-4): 296-299

4. Dakubo JCB, Ohene - Yeboah MOK, Naaeder SB. Blunt abdominal injuries in adults seen in two teaching hospitals in Ghana. Afr J Trauma 2004 2, $63-66$

5. Archampong EQ. Trends in patterns of abdominal injuries as seen at Korle $\mathrm{Bu}$ Teaching Hospital. $23^{\text {rd }}$ Annual Conference of West African College of Surgeons. 1983:123-129(Abstract).

6. Buff LD, Cole FJ. "Alternative" surgery in trauma management. Arch Surg 1998; 133, 1177-81

7. Liebenberg ND, Maasch AJ. Penetrating abdominal wounds: A prospective trials of conservative treatment based on physical signs. $S$ Afr Med J 1988; 74: 231-233. 
8. Moore EE, Moore JB, Van-Duzer-Moore S, Thompson JS. Mandatory laparotomy for gunshot wounds penetrating the abdomen. Am J Surg 1980;140:847-851.

9. Shftan GW. Indications for operation in abdominal trauma. Am J Surg 1960; 99: 657-664.

10. .Navsaria PH, Berli JU, Edu S, Nicol AJ. Nonoperative management of abdominal stab woundsan analysis of 186 patients. South Afr J Surg 2007

11. Leppaniemi AK, Haaipianen RK. Selective nonoperative management of abdominal stab wounds: prospective randomized study. World J Surg 1996; 20: 1101-1105.

12. van Haarst EP, van Bezooijen BPJ, Coene PLO, et al. The efficacy of serial physical examination in penetrating abdominal trauma. Injury 1999; 30: 599-604.

13. Van Brussel $M$, van Hee R. Abdominal stab wounds: a five-year patient review. Eur J Emerg Med 2001; 8: 83-88.

14. Tsikitis V, Biffl WL, Majercik S, et al. Selective clinical management of anterior abdominal stab wounds. Am J Surg 2004; 188: 807-812.

15. 2000 Population and Housing Census: Summary Report of Final Results. Ghana Statistical Services March 2002.

16. Archampong EQ. Closed injuries of the abdomen in an urban tropical surgical centre. West Afr Med J 1969 XVIII: 216 - 221.
17. Adesanya AA, da Rocha - Afodu JT, Ekanem EE, Afolabi IR. Factors affecting mortality and morbidity in patients with abdominal gunshot wounds. Injury 2000;31:397-404.

18. Muckart DJJ, Abdool Carim ATO, King B. Selective conservative management of abdominal gunshot wounds: A prospective study. Br J Surg 1997; 77:652-655.

19. Salim A, Velmahos GC. When to operate on abdominal gunshot wounds. Scandinavian J Surg 2002;91:62-66.

20. Renz BM, Feliciano DV, Unnecessary laparotomies for trauma: a prospective study of morbidity J Trauma 1995; 38: 350 - 6 .

21. Renze BM, Feliciano DV. The length of hospital stay after an unnecessary laparotomy for trauma: A prospective study. J Trauma 1996; 40:187-190.

22. World Health Organization. Executive Summary. National Cancer Control Programmes: Policies Managerial Guidelines. Geneva WHO. 2002: I XXIV

23. .Hasaniya N, Demetriades D, Stephens A. Dubrowskiz R, Barne TV. Early morbidity and mortality of non therapeutic operations for penetrating trauma. Am J Surg 1994; 60:744-747.

24. Feliciano DV, Burch JM, Spjut-Patrinely V, Mattox KL, Jordan GL. Abdominal Gunshot Wounds. An Urban Center's Experience with 300 Consecutive Patients. Ann. Surg 1988; 28: 362-367 